\title{
An analysis of expert knowledge transmission using machine translation services
}

\author{
Hiroshi Suzuki, Reiko Hishiyama \\ School of Creative Science and Engineering, Waseda University \\ Okubo 3-4-1, Shinjuku-ku, Tokyo 169-8555, Japan \\ \{hiroshisuzuki@fuji., reiko@\}waseda.jp
}

\begin{abstract}
Due to globalization, there is an increase in not only the use of machine translation services but also in the risk of failure to transfer. This risk becomes particularly significant if users are transmitting their country's specific knowledge and know-how to exchange cultural information with users in other countries. To mitigate this risk, it is necessary for users to adapt to the translation services in order to improve the translation's accuracy. Thus, in this study we focused on the transmission effect of sharing technical knowledge with a user having a different mother tongue (Chinese) by using a machine translation service. We performed experiments simulating expert knowledge transmission classes and tasks with a system consisting of multilingual chats and a corpus of terminologies. Our evaluation of the transmission reveals how the Chinese knowledge receiver could have learned depending on the pattern of organizational structure and the level of detail of the information. We also found that the use of symbols and numbers was effective. After these simulations and evaluation, we were able to propose how to more effectively use machine translation in the transmission of technical knowledge.
\end{abstract}

\section{CCS Concepts}

-Human-centered computing $\rightarrow$ HCI design and evaluation methods; Collaborative and social computing theory, concepts and paradigms; Interaction design; •Information systems $\rightarrow$ Information systems applications;

\section{Keywords}

multilingual communication; machine translation services; knowledge transmission; language grid

\section{INTRODUCTION}

As a result of globalization, there are increasing opportunities to communicate with people from other countries and to share technical and cultural knowledge for academic

Permission to make digital or hard copies of all or part of this work for personal or classroom use is granted without fee provided that copies are not made or distributed for profit or commercial advantage and that copies bear this notice and the full citation on the first page. Copyrights for components of this work owned by others than ACM must be honored. Abstracting with credit is permitted. To copy otherwise, or republish, to post on servers or to redistribute to lists, requires prior specific permission and/or a fee. Request permissions from permissions@ acm.org.

SoICT '16, December 08-09, 2016, Ho Chi Minh City, Viet Nam

(c) 2016 ACM. ISBN 978-1-4503-4815-7/16/12 . \$15.00

DOI: http://dx.doi.org/10.1145/3011077.3011085 or business purposes. Simultaneously, with the development of the information society, opportunities to use information technology for handing down or sharing technical skill and knowledge are increasing. Hustad [1] focused on how knowledge can be developed and transferred in multinational organizations and how 'communities of knowing' can stimulate these knowledge processes through global collaboration support using ICT. Therefore, as globalization continues, it will become common to use information technology between multiple languages.

As knowledge is transmitted and shared in the global environment, it is estimated that the usage of machine translation services will also increase. However, there are many risks involved with machine translation-failure to transmit, knowledge recognized in error, important parts lacking, etc. -due to the inaccuracy of current machine translation systems. We therefore examine how users can adapt their approach to machine translation in order to decrease the risk of failure to transmit. Specifically, we conduct experiments in transmitting technical knowledge using multilingual expert knowledge transmission that consists of a machine translated multilingual chat using a machine translation service and technical term corpus. We identified the most accurate and efficient way of transmitting technical knowledge using machine translation by analyzing experimental data and the evaluation results.

In the next section of this paper, we overview the previous studies related to knowledge transmission and explain the studies that have conducted information transmission using machine translation in multilingual environments and then describe the position of this study. The third section introduces our proposal and the experiment we performed. In section four, we present our findings, and the fifth section discusses the findings and presents an effective method of transmitting expert knowledge using machine translation. We conclude in the final section with a brief summary and mention of future work.

\section{RELATED WORKS}

We cite the YMC-Viet [2] Project as a case where individuals actually use machine translation for transmitting and sharing knowledge or information. This project, which aims at supporting agriculture in Vietnam by transmitting knowledge, uses a system that consists of the machine translation of Language Grid [3] to enable Japanese experts to share agricultural knowledge, skills, and related know-how with Vietnamese people. For this project, Kita et al.[4] evaluated and analyzed the transmission effect of several patterns used 
in the project, including various transmitting techniques, machine translation, human translation, and the rewriting of original sentences. Otani et al.[5] analyzed the communication $\log$ and the results of interviews administered to knowledge contributors and learners and found that there is different styles between the roles that the two types of user have, namely, that experts possess technical knowledge about agriculture and that Vietnamese people possess local climate knowledge, which they exchange with each other. The researchers involved in that study proposed improving communication protocol as a way to overcome different styles and supporting the community of collecting knowledge by the experts.

The studies above have illustrated the difficulties in knowledge transmission services in multilingual environments along with its beneficial characteristics. Although the manner of organization and technical improvement in terms of the accuracy of machine translation and the ways it is being improved have been clarified, there is not much knowledge about the comparative effect on the differences of organization and different combinations of translation service. Therefore, it is necessary to clarify the basic improvement effect in the manner of organizing knowledge transmission and the way of using machine translation services.

Gao et al.[6] and $\mathrm{Xu}$ et al.[7] focused on methods to obtain a valid transfer effect from how to view the results of a translation. Gao et al. analyzed the effect of highlighting the important part of the sentence to be machine translated on the intelligibility of the translated sentence. Xu et al. analyzed the effect of entering two types of sentence that have the same meaning and different grammatical structures in the machine translation and outputting both at the same time against a conversational partner.

There have also been studies [8] [9] that focused on referring expression for mutual understanding of communication mediated by machine translation. The literature [8] analyzed multilingual communication supported with machine translation by setting two people with a different mother tongue a task to organize a set of figures while communicating with each other using chat. The initial work [9] was extended [8] by using three languages. These studies paid attention to referring expression as a specific factor of information transmission and designed the task that contains hints such as figures' shape and order. In the present study, we consider the appearance of various actions to transfer information. In other words, we assume a different environment than [8] and [9] by setting a task to explore the method of transferring knowledge in a multi-language environment. Also, there are differences in the environment of the experiment of this study, which assumes an asymmetrical environment. In this study, participants were not permitted to share information before the experiment, and the levels of knowledge between provider and recipient were different.

Incidentally, Szulanski[10] noted the importance of considering knowledge transmission - not action and model, but rather the transfer process - and mentions the need of a thinking-mediated method for the management of knowledge transfer. This is essentially an organizational mechanism designed to support the knowledge transfer in addition to the knowledge itself to be transmitted. This study examines tasks assuming an information environment that includes technical terms and expertise considered common in the corporate world. From the above, this study's target, where we consider the organization mechanism of a multilanguage environment suitable for use in a machine translation from an experiment, as well as make suggestions about how to enhance the validity of knowledge transfer by the intervention of the machine translation, is different from literature [8] [9] that focuses on the reference expression.

\section{APPROACH}

\subsection{OVERVIEW}

In this study, we establish a knowledge provider offering knowledge and a knowledge receiver who learns it. We examine the effect of knowledge transmission involving technical knowledge from the knowledge provider to the knowledge receiver. As stated above, a systematic mechanism to support both the management of knowledge being transmitted and the system itself is important. In contrast, in a process where knowledge is transmitted via communication using a machine translation service in companies or a social community, communications that are the same and different are mixed, so the effects of knowledge transmission will probably be different depending on the language environment. Furthermore, the best way to support and use multilingual services is more complicated in these situations, which makes it necessary to enforce the most adequate use for the environment of the organization. Furthermore, it is indispensable to estimate whether a case involves knowledge that is closely correlated or that is highly technical. For example, the work flow and explanation of operational procedure correspond to that. It is also important to devise a means of support for using the machine translation, not just to wait for the translation accuracy to develop and improve. This makes it also necessary to determine how to transmit knowledge more accurately and efficiently by having the user adapt to it on their side. In the present study, we consider the effect of knowledge transmission with the goal of supporting practical use. The issues covered in this study are summarized below.

1. This study clarifies how to transmit knowledge efficiently by using machine translation services and supposing a practical place on the assumption that the knowledge provider and receiver compose a multilingual environment.

2. This study clarifies how to maximize the accuracy of knowledge transmission using machine translation by testing several patterns of the organizational learning of knowledge receivers.

3. This study devises effective methods for the concrete utilization of machine translation services to share complicated or technical knowledge correlated with each other.

We determine the transmission effect by experimenting on knowledge transmission from knowledge provider to receiver using expert knowledge transmission services. In this study, each experiment includes one knowledge provider (Japanese) and various patterns of groups having three knowledge receivers (Japanese or Chinese). The group patterns are discussed in section 3.3. 


\subsection{EXPERIMENTAL SYSTEM}

The system configuration of the expert knowledge transmission services used in this study is given in Fig. 1. This system is an application featuring functions for effective transmission and learning, namely, a corpus of technical terms and a memo, that was added to. the multilingual chat system using the Language Grid's [3] machine translation service. The system uses the Multilingual Studio [11] to connect to the Language Grid. To operate the translation service between Japan and China, it uses J-Server, which is Kodensya Co.'s machine translation service. Incidentally, this system's multilingual chat system contains the faculty of translation repair; whether or not to use it is the choice of the subjects. The interface of the system is given in Fig. 2, which is divided into four parts: the corpus of technical terms on the left, the multilingual chat at center, the part for the knowledge provider to acquire technical knowledge by a video at top right, and the part where subjects take notes on their own at bottom right. This study treats the method of manufacturing the Sake, Japanese rice wine, as the exclusive knowledge; so the corpus of the technical terms incorporates 20 technical terms expected to be searched and that are compatible between Japanese and Chinese.

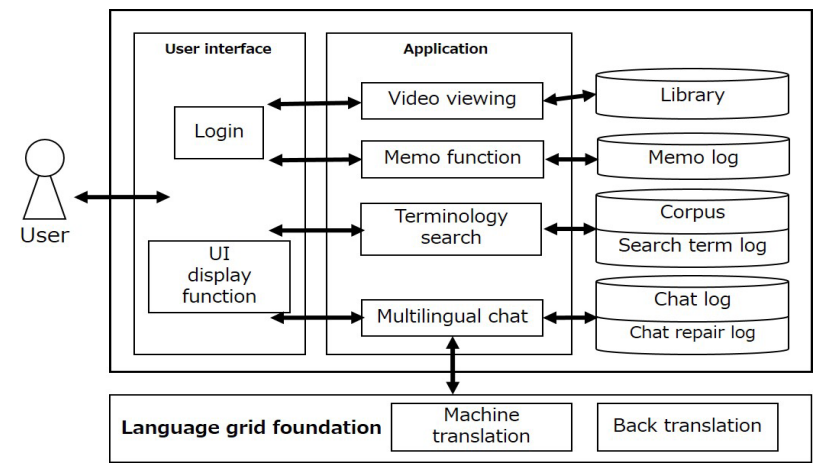

Figure 1: System configuration diagram.

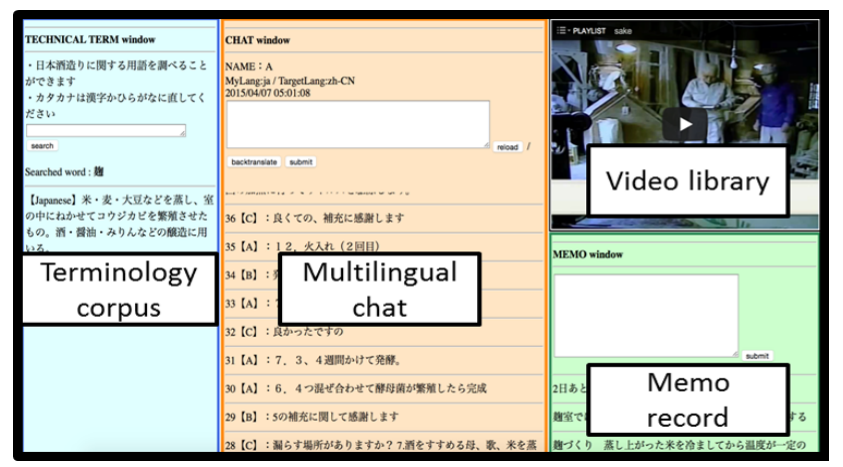

Figure 2: System interface (Japanese).

\subsection{EXPERIMENTATION}

The procedure of the experiments (shown in Fig. 3) is as follows.

1. First, an exclusive knowledge provider learns the knowledge to teach the knowledge receiver by reproducing a "how to make sake" video in the video library part of the system by himself.

2. After the provider's learning, three subjects log in to the system as knowledge receivers, and the provider

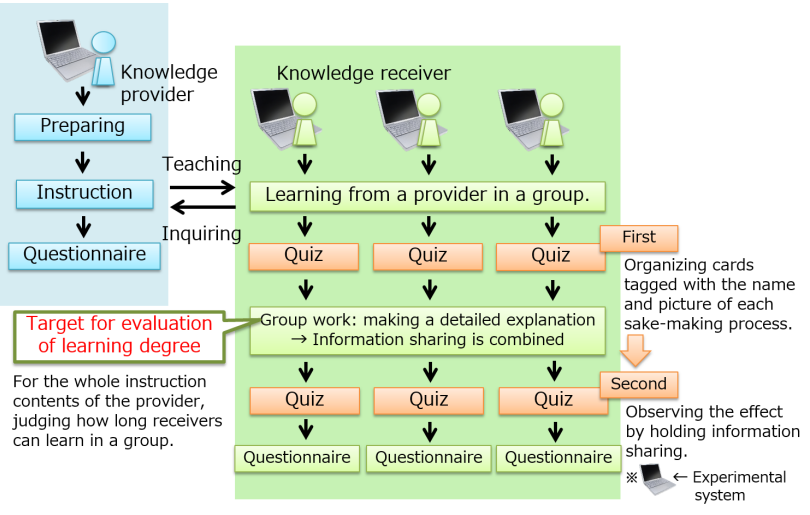

Figure 3: Flow of experiment.

teaches the receivers the knowledge by using multilingual chat principally along with some other functions. This stage, which takes 40 minutes, is regarded as the knowledge transmission. During this time, the three knowledge receivers can ask the provider questions and use the technical term corpus.

3. After the knowledge transmission from the provider to receivers, to assess the understanding, the receivers solve a sequencing problem of how to make sake. This is done by organizing cards tagged with the name and picture of each process in the sake-making procedure. The sequencing problem consists of 12 cards, with one card per process for a total of 12 processes. The row of the correct answer and each processes' outline are as shown in Fig. 4.

4. After this, all the knowledge receiver has to deal with is group work (chat). The subject is "Explain sake production to a group of people who have little knowledge about it as thoroughly as possible in a group", and the knowledge receiver must put this explanation up on the multilingual chat screen. This output is the target to evaluate the general understanding and effect by the knowledge transmission. This group work stage is regarded as the information sharing.

5. After the group work, knowledge receivers solve the sequencing problem again. Finally, all subjects respond to a questionnaire about this experiment.

These experiments examine three groups of three knowledge receivers: the first consisting of three Japanese, the second of three Chinese, and the third of two Chinese and one Japanese. All knowledge providers in the experiments are Japanese. We conducted this experiment four times for each pattern, so 12 times in total. In the next section, we investigate accurate and effective methods of transmission using machine translation by comparing the results of each experiment pattern by observing the multilingual chat transcripts of each experiment.

\section{RESULTS}

\subsection{BASIC INTELIGIBILITY}

The average positive answer ratio of the sequencing problem related to the sake brewing process used to evaluate receivers' fundamental understanding depending on patterns is given in Fig. 5. The first time to answer this problem 


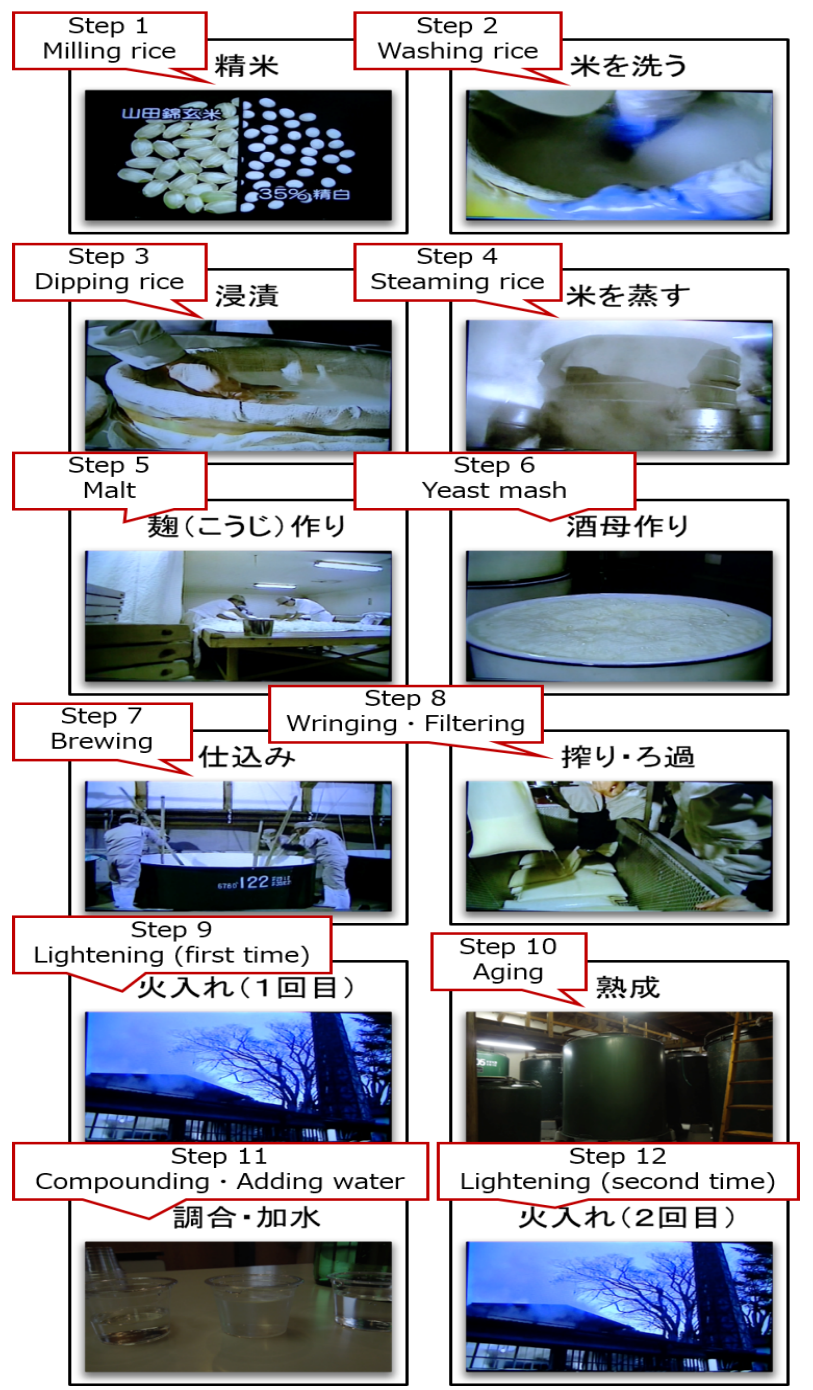

Figure 4: Example of cards used in Sequencing Problem with the row of the correct answer and each processes' outline.

is the value obtained after transmitting from the knowledge provider and the second is after the group work as knowledge sharing.

From Fig. 5, we can see dispersion between patterns about the positive answer ratio before group work - the ratio of all patterns is more than 80 percent after that. These results suggest that the transmission of the fundamental knowledge even in the case of Chinese only is successful to a certain degree; moreover, the positive answer ratio can be improved to around 80 percent by information sharing.

\subsection{OVERALL UNDERSTANDING LEVEL OF THE KNOWLEDGE TRANSMISSI- ON}

Next, to clarify the overall understanding level of the knowledge transmission process, including detailed information, we show a value called "learning degree" that explains how much detailed knowledge the receivers learned for the instruction range that the knowledge provider provided in the knowledge transmission stage. In this work, we define the learning degree as the value (ratio) from dividing the

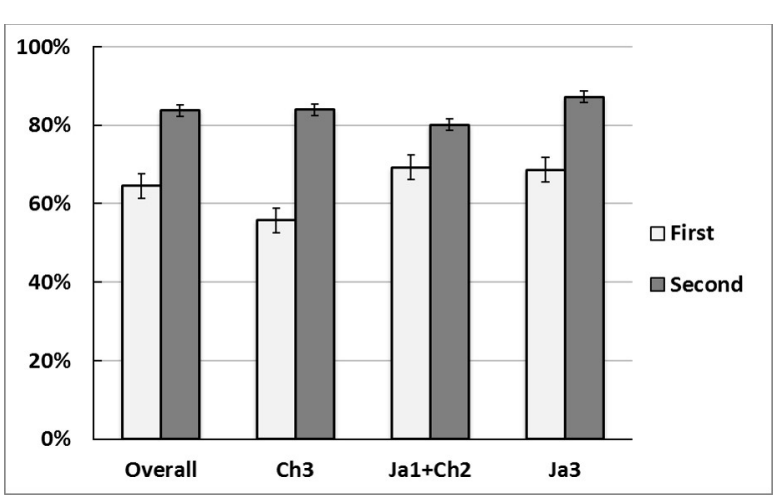

Figure 5: Ratio of positive answer of Sequencing Problem by experiment's pattern.

score that we give to mark the output of the receivers' group work, which is explaining how to make sake, using the original criterion, by that we mark the chat transcript written by the knowledge provider with the same criterion. In doing this, we asked bilingual Japanese and Chinese volunteers to translate the explanation written in Chinese and marked that after translating. The marking criteria for calculating the learning degree are given in Table 1.

Table 1: marking criteria.

\begin{tabular}{|c|c|}
\hline $\begin{array}{l}\text { Conditions for added } \\
\text { point }\end{array}$ & $\begin{array}{l}\text { Added point (slight mis- } \\
\text { take) }\end{array}$ \\
\hline $\begin{array}{l}\text { There is a reference to } \\
\text { each important step for } \\
\text { the Sake manufacturing }\end{array}$ & $\begin{array}{l}3 \text { points for each word (2 } \\
\text { points). }\end{array}$ \\
\hline $\begin{array}{l}\text { Detailed description is in- } \\
\text { volved in each step. }\end{array}$ & $\begin{array}{l}2 \text { points for each word (1 } \\
\text { point) }\end{array}$ \\
\hline
\end{tabular}

The average learning degrees of each experiment pattern calculated by the criteria are given in Fig. 6 .

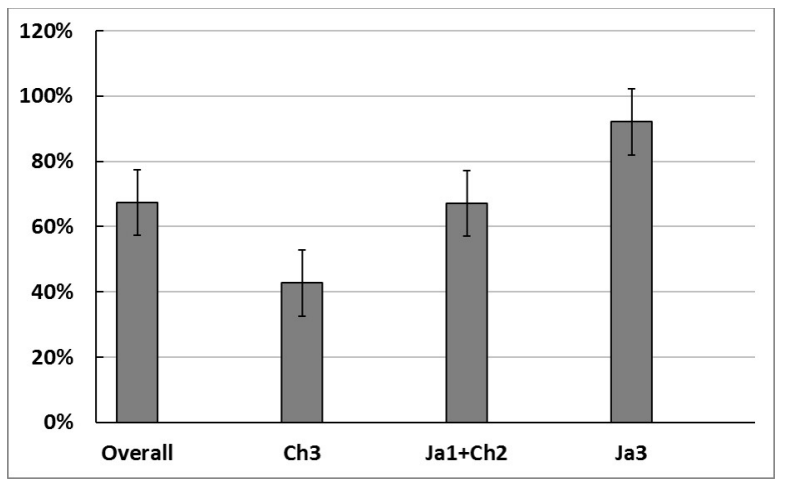

Figure 6: Learning degree for knowledge transmission by experiment pattern.

From Fig. 6, we see that the average of the group of three Japanese subjects is much higher than that of the three Chinese (t-test: $\mathrm{p}<0.05)$. Specifically, there is a difference of 50 percent between the group sharing a mother tongue with the provider and the group that does not. We also see that the average of two Chinese and one Japanese is higher than that of three Chinese (t-test: $\mathrm{p}<0.05)$. This demonstrates that adding a same mother tongue receiver to a different mother tongue receivers' group can enhance the quantity of knowledge.

Although it has been assumed that conducting multilingual communication by machine translation would have poor 
results, our evaluation here suggests that the effect of information sharing from receivers learning by the same mother tongue as the knowledge provider is high enough to mitigate any bad effects of the machine translation.

\section{ANALYSIS}

\subsection{EFFECTIVE TEACHING CASE}

This section considers an effective method of transmission in expert knowledge transmission while using machine translation services. In Fig. 7, we show the "learning degree" results of each experiment as the intelligibility for the sum of the knowledge transmission.

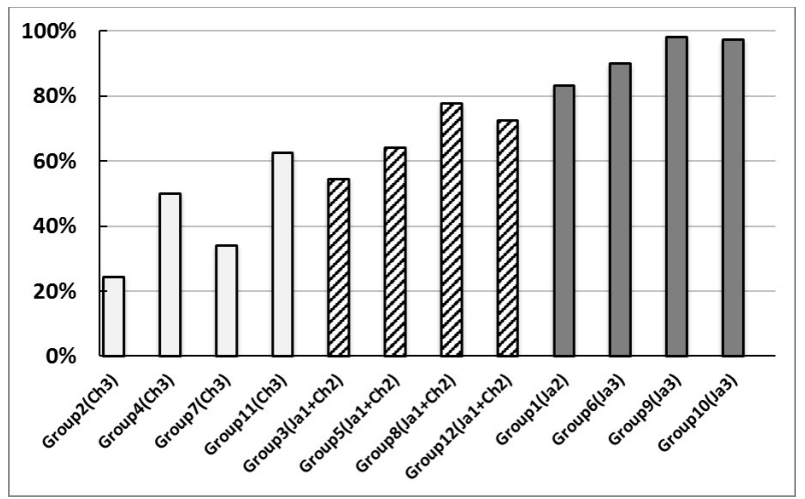

Figure 7: Learning degree for knowledge transmission of each experiment.

The number of experiments were given in the order of performing the experiments and arranged in Fig.7 for each experiment pattern. Examples of each knowledge provider's chat log in the knowledge transmission stage in three experiments (experiments no. 11, 8, and 12) by using an original thread and translation thread are shown.[12] $]^{1}$

\section{- EXPERIMENT NO.11}

The original thread and the translation thread of experiment no. 11 are given in Table 2. This experiment uses the pattern of three Chinese as the knowledge receiver to a Japanese provider.

In this transmission, first the knowledge provider presents the series of the events of how to make sake, from the first process to the final process, and then adds detailed explanations to each of the presented processes. As the specific feature in this experiment, in the stage of presenting the series of the events, the provider encloses the name of a process by using the "「」" symbol and orders processes by using the " $\rightarrow$ " symbol to explain turn. When we see machine translated sentences in this part, these symbols do not change into other symbols or words, namely, "「」" encloses the name of a process and " $\rightarrow$ " connects the process, like the original, continuously, and that is reflected in the translation thread. Moreover, in the stage of adding detailed explanations to each process, the provider connects the

\footnotetext{
${ }^{1}$ In the original thread, Japanese is spoken by the receiver in a multilingual chat and is directly used. In other words, it is the same as what is displayed in the chat window when using the system. In the translation thread, the chat content is displayed on the system when the native language is set to Chinese and is obtained by the translation into Japanese.
}

Table 2: Knowledge transmission of experiment no. 11.

\begin{tabular}{|c|c|}
\hline Original Thread & Translation Thread \\
\hline $\begin{array}{l}\text { Malt making }\lrcorner \rightarrow \text { Yeast } \\
\text { mash making }\lrcorner \rightarrow\lceil\text { Brewing }\rfloor \\
\rightarrow\lceil\text { Wring } \cdot \text { filtration }\rfloor \rightarrow\end{array}$ & $\begin{array}{l}\text { I Production of malt }\rfloor \rightarrow \\
\lceil\text { Yeast mash production }\rfloor \\
\rightarrow\lceil\text { Training }\lrcorner \rightarrow \text { 「Wring } \cdot \\
\text { filtration }\rfloor\end{array}$ \\
\hline $\begin{array}{l}\text { Lightening (first time) }\rfloor \rightarrow \\
\ulcorner\text { Aging }\lrcorner \rightarrow \Gamma \text { Compounding } \\
\text { Adding water }\rfloor \rightarrow\lceil\text { Lighten- } \\
\text { ing (second time) }\rfloor \rightarrow\end{array}$ & $\begin{array}{l}\text { TFire pot (first time) }\rfloor \rightarrow \\
\lceil\text { Maturation }\lrcorner \rightarrow \text { Com- } \\
\text { pounding } \cdot \text { Adding water }\rfloor \rightarrow \\
\lceil\text { Fire pot (second time) }\rfloor\end{array}$ \\
\hline $\begin{array}{l}\text { \Malt making }\rfloor=\text { To saccha- } \\
\text { rify the starch of rice, you } \\
\text { sprinkle the malt mold on the } \\
\text { rice. }\end{array}$ & $\begin{array}{l}\lceil\text { Malt making }\lrcorner=\text { You sprin- } \\
\text { kle the malt mold in the rice } \\
\text { and saccharify the starch of } \\
\text { rice. }\end{array}$ \\
\hline $\begin{array}{l}\text { TYeast mash making }\rfloor=\text { You } \\
\text { make the yeast mash by mix- } \\
\text { ing the malt, steamed rice, } \\
\text { lactic acid, water. }\end{array}$ & $\begin{array}{l}\text { TYeast mash production }\rfloor \\
=\text { Malt, rice steamed and } \\
\text { mixed, lactic acid, and water } \\
\text { make yeast mash. }\end{array}$ \\
\hline
\end{tabular}

name of the process and the detailed explanation by using "=", as in the expression "this is ..." or "SVC". Although the position of this "=" symbol changes in the translation part of the thread, it could also to some extent transmit the same expression as the original thread in the other part where the "=" position does not change.

- EXPERIMENT NO. 8

As with experiment no. 11, we show examples of the chat $\log$ in the knowledge transmission of experiment no. 8 in Table 3 . The pattern in this experiment is two Chinese and one Japanese as the receiver and one Japanese provider.

Table 3: Knowledge transmission of experiment no. 8.

\begin{tabular}{|l|l|}
\hline Original Thread & Translation Thread \\
\hline 1 Polishing rice & 1 Polishing rice \\
\hline $\begin{array}{l}\text { The raw material of Japanese } \\
\text { sake is brown rice. }\end{array}$ & $\begin{array}{l}\text { The raw material of Japanese } \\
\text { sake is brown rice. }\end{array}$ \\
\hline $\begin{array}{l}\text { Use the machine to remove } \\
\text { the outermost skin of the } \\
\text { brown rice. }\end{array}$ & $\begin{array}{l}\text { Use the machine to remove } \\
\text { the outermost skin of brown } \\
\text { rice. }\end{array}$ \\
\hline 3 Dipping & 3 Dipping \\
\hline $\begin{array}{l}\text { The washed rice is immersed } \\
\text { in water and allowed to ab- } \\
\text { sorb the water. }\end{array}$ & $\begin{array}{l}\text { The washed rice is immersed } \\
\text { in water and allowed to ab- } \\
\text { sorb the water. }\end{array}$ \\
\hline
\end{tabular}

As the process of knowledge transmission, in experiment no. 11, the provider began the explanation by presenting the series of the events. In contrast, in experiment no. 8 , the provider presents the detailed description in order from the beginning. As for the manner of chatting, when explaining each process, he first mentions only the name of the process, tagging its start with a number, and then adds the explanation to it in the next contribution. On this occasion, we can see that he tries to make each sentence as simple as possible by dividing sentences if the volume of information is too high. In addition, we can see that there are many contributions that are simple for explaining each process and information could have been transmitted to some extent by seeing the translated thread of experiment no. 11. We actually received comments showing the effectiveness of this - one of the Chinese participants indicated in the post-experiment questionnaire that it was easy to understand by using numbers. 
- EXPERIMENT NO.12

In Table 4, we show examples from the chat log in the knowledge transmission of experiment no. 12. This experiment follows the same pattern as no. 8, namely, using two Chinese and one Japanese as the receiver and one Japanese provider.

Table 4: Knowledge transmission of experiment no. 12.

\begin{tabular}{|l|l|}
\hline Original Thread & Translation Thread \\
\hline Step 2 "Blank" Washing rice & Mistranslation \\
\hline $\begin{array}{l}\text { Step 3 "Blank" Dipping } \\
\text { "Blank" The rice is soaked in } \\
\text { water for water absorption. }\end{array}$ & $\begin{array}{l}\text { Step 3's rice is soaked in wa- } \\
\text { ter for water absorption. }\end{array}$ \\
\hline $\begin{array}{l}\text { Step 4 "Blank" Steaming rice } \\
\text { "Blank" It is steamed for } \\
\text { about one hour in a machine } \\
\text { named 「Koshiki」. }\end{array}$ & $\begin{array}{l}\text { Step 4 Steaming rice. It is } \\
\text { chine }\end{array}$ \\
\hline $\begin{array}{l}\text { Steamed rice to be used is di- } \\
\text { vided into several steps after } \\
\text { this. }\end{array}$ & $\begin{array}{l}\text { Steamed rice will be used in } \\
\text { the subsequent process. }\end{array}$ \\
\hline
\end{tabular}

In terms of the order of the knowledge transmission, the provider gives a detailed explanation of each process one by one starting from the first process, as in experiment no. 8. As the way of contributing a message, in experiment no. 12, he present the name of the process with the number indicating order and explains about the process at the same time, using "space" between the name of the process and the explanation. However, when we look at the translation result from Japanese to Chinese, we can see several utterances that have no "space", so that the process name and its explanation are mixed together. When we look at the translation thread, we can confirm that meaning is transmitted to some extent, but some utterances cause mistranslation. Hence, it is assumed that it is better to use the "=" symbols or to present a process and explain about it at the same time.

\section{- CONVERSATION METHOD IN THE GROUP WO-} RK

Experiments no. 8 and 12 used two Chinese and one Japanese as the knowledge receiver and one Japanese knowledge provider. As previously mentioned, we kno$\mathrm{w}$ that if we add a Japanese receiver to the two Chinese receivers having different mother tongues, the learning degree (group's learning range) is higher than when using only Chinese as knowledge receiver from Japanese. If we compare the group work chat logs of the two Chinese and one Japanese pattern, we see that in experiment nos. 8 and 12, Japanese and Chinese participants communicate about sake production by using numbers and adding them in each process. For the Japanese, when they share an additional explanation to the Chinese about the missing information, and for the Chinese, when they ask questions to the Japanese about the processes that they have not learned, using numbers makes it easy for them to understand what process is being discussed. We therefore assume this is an effective means of improving the accuracy of knowledge transmission. This phenomenon is observed in the group work of experiment no. 5. In contrast, in experiment no. 3, the learning degree is the worst, and using numbers for communication is observed only once, after the communication about the third process.

\subsection{SUMMARY OF EACH TEST CASE}

To summarize the above, in the experiments having good learning degree results, we saw that each utterance is simple, and when the description is long, the providers divide the contribution into multiple statements. Furthermore, to express order conjunctions, they use numbers or symbols such as " $\rightarrow$ " instead of conjunctions such as "next", "moreover", or "then", and to express "SVC", they also use symbols or carry explanation contents or the "C " of "SVC" into the next contribution.

In this study, we did not give the subjects any rules. Even so, we observed chat logs where the above rules were practiced naturally in experiment no. 4 in addition to experiments no. 8 and 12. Furthermore, while we deal with technical knowledge as the subject of the knowledge transmission, we also observed numbers being used in experiments no. 8 and 12 and symbols being used in experiment no. 11 . When we look at the chat logs of the knowledge transmission process in experiments no. 2 and 7, whose learning degree values are both low, we can see that both their providers used conjunctions or particles to express knowledge, with only rare use of numbers or symbols. We therefore assume that using general representations of a language is not the best way to execute knowledge transmission.

\subsection{KNOWLEDGE TRANSMISSION MET- HOD}

In this study, we saw many examples of using numbers and symbols in the experiments having good learning degree. We assume these numbers and symbols were effective because their characters are barely affected by translation and their meanings are universally identifiable to some extent. In this study, we deal with knowledge information, the manufacturing process of sake, that has definitely predetermined work and order as the technical knowledge for transmission. If we do such knowledge transmission, it is clear that using numbers and symbols is effective. The behavior described above may be considered behavior that represents human adaptation to the machine translation. Now, we summarize the method of knowledge transmission that is considered to be effective and present a knowledge transmission method that enables effective transmission while using machine transmission based on the knowledge obtained in this study. In Fig. 8 , we present the transmission order discussed above.

In addition, as a note of caution, it is assumed that dividing a sentence into multiple short sentences will result in a better translation. Therefore, if we want to ensure high translation accuracy and good results, it seems that corresponding, for example, dividing contribution after "=", surrounding words with "「」", and so on, will help.

In the above method, the way of rewriting a sentence using symbols and numbers is designated in detail from Steps 1 to 4 so that the quality of the knowledge transmission with the machine translation is maintained constantly even if all knowledge providers are different. On the other hand, if we assume practical cases such as using machine translation services to explain a country' $\mathrm{s}$ culture to foreign tourists or to provide human resources education in multinational companies, it is fair to say that the action and the course of knowledge transmission will vary depending on the person doing the teaching, on the knowledge being handled, and on the situation. It is therefore important to develop a more versatile transmission order so that each knowledge provider 


\begin{tabular}{|c|c|c|}
\hline Step 1 & \multicolumn{2}{|r|}{$\begin{array}{l}\text { Introduce the flow with using " }\lceil\text { Name of process }\rfloor \text { " and } \\
" \rightarrow \text { ". If posted sentence is long, posts may be divided } \\
\text { into multiple sentences. }\end{array}$} \\
\hline \multirow{2}{*}{ E.g. } & (Ja) & $\begin{array}{l}\text { 「精米」 } \rightarrow \text { 「洗米」 } \rightarrow \text { 「浸漬」 } \rightarrow \text { 「蒸 } \\
\text { 米」 }\end{array}$ \\
\hline & (En) & $\begin{array}{l}\text { "Milling rice" } \rightarrow \text { "Washing rice" } \rightarrow \text { "Dipping } \\
\text { rice" } \rightarrow \text { "Steaming rice" } \rightarrow\end{array}$ \\
\hline Step 2 & \multicolumn{2}{|r|}{$\begin{array}{l}\text { After introducing the flow, explain the introduced } \\
\text { processes one by one, giving a number. Input " } 1 \text { " as the } \\
\text { first number and contribute. }\end{array}$} \\
\hline E.g. & \multicolumn{2}{|l|}{1} \\
\hline Step 3 & \multicolumn{2}{|r|}{$\begin{array}{l}\text { Then, using " }=\text { ", explain the first process after input " } \\
\Gamma_{\text {Name of first process }\rfloor " .}\end{array}$} \\
\hline \multirow{2}{*}{ E.g. } & (Ja) & $\begin{array}{l}\text { 「精米」= 精米機を用いてコメの余分な外殼 } \\
\text { を削り取る }\end{array}$ \\
\hline & (En) & $\begin{array}{l}\text { "Milling rice" = scrape off extra outer shell of the } \\
\text { rice using a rice cleaning machine. }\end{array}$ \\
\hline Step 4 & \multicolumn{2}{|r|}{$\begin{array}{l}\text { For all processes after the second, perform like Steps } 2 \\
\text { and } 3 \text { to explain the first process of Sake production. }\end{array}$} \\
\hline \multirow{8}{*}{ E.g. } & \multirow{4}{*}{ ( Ja) } & 2 \\
\hline & & 「洗米」＝米を洗い、削つた籾款を除去する \\
\hline & & 3 \\
\hline & & 「浸漬」＝米を水に浸し、吸水させる \\
\hline & \multirow{4}{*}{ (En) } & 2 \\
\hline & & $\begin{array}{l}\text { "Washing rice" = Wash the rice to remove the } \\
\text { husk. }\end{array}$ \\
\hline & & 3 \\
\hline & & $\begin{array}{l}\text { "Dipping rice" = Soak the rice in water until water } \\
\text { is absorbed. }\end{array}$ \\
\hline N.B.1 & \multicolumn{2}{|r|}{$\begin{array}{l}\text { Try to make as simple sentences as possible. Posts should } \\
\text { be } 1 \text { per sentence. }\end{array}$} \\
\hline N.B.2 & \multicolumn{2}{|c|}{$\begin{array}{l}\text { Therefore, multiple posts are needed when the } \\
\text { description is longer. }\end{array}$} \\
\hline
\end{tabular}

Figure 8: Effective knowledge transmission.

can choose the use pattern of the order freely depending on the situation and arrange it in an original way in addition to following the method, as in Fig. 8, where the rewriting result is limited to one pattern. Then, a more versatile transmission order can be achieved, as in Fig. 9.

In Fig. 8, the transmission order gives users suggestions in detail by showing them a procedure. In contrast, in Fig. 9 , we extract the various usages of symbol and number in the multilingual chat and show them as an individual technique following any pattern with an example sentence. The provider may choose and execute techniques freely (Fig. 9) and arrange them how they like depending on the situation.

This two methods of using the machine translation were made by extracting characteristics with a rule from the system's use history of experiments having a high value of original index. The index was defined originally as the criteria expressing effectiveness of knowledge transmission through the entire experiment. In contrast, from the experiments having low value, a method similar to the above was not extracted with a rule. If we consider the probability of mistranslated Chinese-Japanese sentences, the method extracted from the experiments is not always effective. However, although mistranslations occasionally appear, it seems that it is easy for knowledge receivers to adapt to providers' teaching and ma-

\begin{tabular}{|c|c|c|c|}
\hline \multirow{3}{*}{$\begin{array}{c}\text { Tech } \\
1\end{array}$} & \multirow{3}{*}{$\begin{array}{l}\begin{array}{l}\text { Use tech of symbol } \\
\text { and number }\end{array} \\
\begin{array}{l}\text { Put important words } \\
\text { and phrases between } \\
\text { "「" and "」". }\end{array}\end{array}$} & \multicolumn{2}{|c|}{ Examination of importing sentence } \\
\hline & & ( Ja) & $\begin{array}{l}\text { 「精米機」を用いてコメの余 } \\
\text { 分な外款を削り取る }\end{array}$ \\
\hline & & (En) & $\begin{array}{l}\text { Scrape off extra outer shell of the } \\
\text { rice using "a rice cleaning } \\
\text { machine". }\end{array}$ \\
\hline \multirow{4}{*}{$\begin{array}{c}\text { Tech } \\
2\end{array}$} & \multirow{4}{*}{$\begin{array}{l}\text { Use } "=" \text { to explain a } \\
\text { word or phrase. }\end{array}$} & $\begin{array}{l}\text { e.g.1 } \\
\text { (Ja) }\end{array}$ & $\begin{array}{l}\text { 「精米」=精米機を用いてコ } \\
\text { メの余分な外殻を削り取る }\end{array}$ \\
\hline & & $\begin{array}{l}\text { e.g.1 } \\
(E n)\end{array}$ & $\begin{array}{l}\text { "Milling rice" = scrape off extra } \\
\text { outer shell of the rice using a rice } \\
\text { cleaning machine. }\end{array}$ \\
\hline & & $\begin{array}{c}\text { e.g.2 } \\
\text { (Ja) }\end{array}$ & 工程 1 = 精米 \\
\hline & & $\begin{array}{l}\text { e.g.2 } \\
\text { (En) }\end{array}$ & Process $1=$ Milling rice \\
\hline \multirow[b]{2}{*}{$\begin{array}{c}\text { Tech } \\
3\end{array}$} & \multirow{2}{*}{$\begin{array}{l}\text { Sustain words or } \\
\text { phrases in the context } \\
\text { by " } \rightarrow \text { " to present the } \\
\text { order. }\end{array}$} & \multicolumn{2}{|c|}{$\begin{array}{l}\text { 「精米」 } \rightarrow \text { 「洗米」 } \rightarrow \text { 「浸漬」 } \\
\rightarrow \text { 「蒸米」 } \rightarrow\end{array}$} \\
\hline & & \multicolumn{2}{|c|}{$\begin{array}{l}\text { "Milling rice" } \rightarrow \text { "Washing } \\
\text { rice" } \rightarrow \text { "Dipping rice" } \rightarrow \text { "Steaming } \\
\text { rice" } \rightarrow\end{array}$} \\
\hline \multirow{4}{*}{$\begin{array}{c}\text { Tech } \\
4\end{array}$} & \multirow{4}{*}{$\begin{array}{l}\text { Use numbers to } \\
\text { present the order. }\end{array}$} & \multirow{2}{*}{ (Ja) } & 1 精米 \\
\hline & & & 2 洗米 \\
\hline & & \multirow{2}{*}{ (En) } & 1 Milling rice \\
\hline & & & 2 Washing rice \\
\hline \multirow{6}{*}{$\begin{array}{c}\text { Tech } \\
5\end{array}$} & \multirow{6}{*}{$\begin{array}{l}\text { To make a sentence } \\
\text { brief, divide a } \\
\text { contribution finely } \\
\text { with using symbol and } \\
\text { number. }\end{array}$} & \multirow{3}{*}{ (Ja) } & 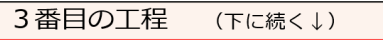 \\
\hline & & & $\begin{array}{l}\text { 浸漬 } \quad(\text { 下に続 }<\downarrow) \\
\end{array}$ \\
\hline & & & 米を水に浸し、吸水させる \\
\hline & & \multirow{3}{*}{ (En) } & Third process (follow below $\downarrow$ ) \\
\hline & & & Dipping rice (follow below $\downarrow$ ) \\
\hline & & & $\begin{array}{l}\text { Soak tne rice in water until water } \\
\text { is absorbed. }\end{array}$ \\
\hline $\begin{array}{c}\text { N.B. } \\
1\end{array}$ & \multicolumn{3}{|c|}{$\begin{array}{l}\text { Try to make as simple sentences as possible. Posts should be } 1 \\
\text { per sentence. }\end{array}$} \\
\hline $\begin{array}{c}\text { N.B. } \\
2\end{array}$ & \multicolumn{3}{|c|}{$\begin{array}{l}\text { Therefore, multiple posts are needed when the description is } \\
\text { longer. }\end{array}$} \\
\hline
\end{tabular}

Figure 9: Effective knowledge transmission: more versatile version.

chine translation by teaching along the method systematically.

\section{GENERALIZATION OF THE RECIPE}

In this study, we adopted "how to make sake" as the knowledge to be transmitted to foreigners with a machine translation service. In this knowledge, there are set processes that need to be determined, and we consider it an important point of evaluation that their contexts are precisely learned by the knowledge receiver. Therefore, Fig. 9's more versatile transmission order, formed by utilizing info obtained in the analysis, is considered effective for transmitting another knowledge that has a clear procedure, e.g., alternative methods of manufacturing food, or procedures related to business in some way. However, this transmission order does not always work adequately for another knowledge. Therefore, when we handle other knowledge for transmitting, it is necessary to adapt the transmission order while considering the unique characteristics of that transmission. As one example, we introduce how the traditional wedding style of Japan [13] is handled as the transmitted knowledge. In contemporary times, the traditional Japanese wedding 
style features the " exchange of the ring" as a key element in the flow of the ceremony. However, this process was not included in ancient times, which gives rise to the necessity of adding a new activation and an example sentence that symbolize the meaning for why you could have added or omitted this process as the thing which is not substantial on the old ceremony in the transmitting. The part that is added to Fig. 9's transmission order when the knowledge provider transmits the traditional Japanese wedding style using the machine translation is as shown in Fig. 10.

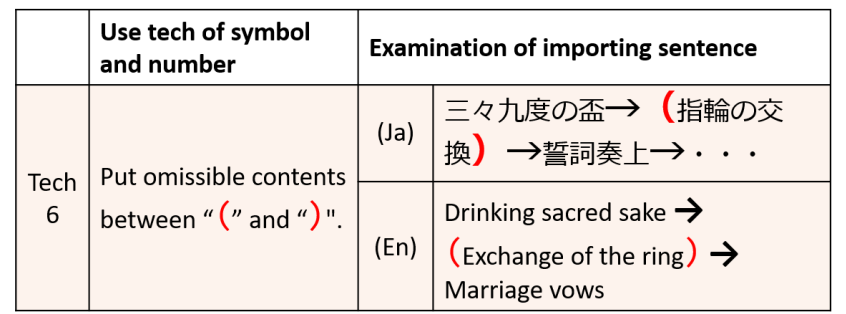

Figure 10: Part that is added when knowledge provider transmits traditional Japanese wedding style.

\section{CONCLUSION}

In this study, we investigated how to carry out the knowledge transmission accurately and effectively with machine translation from the users' point of view assuming a practical scene based upon a multi-lingual environment. Our analysis of results on transmitting basic knowledge about sake production showed that the Chinese-only group pattern, which consisted of receivers having a different mother tongue to the knowledge provider, could have enjoyed knowledge collectively in the knowledge transmission stage enough to improve the individual percentage of correct answers to 80 percent by sharing information. In addition, our evaluation and analysis of the learning degree of each group for the whole knowledge range that providers teach showed that adding no more than a receiver having the same mother tongue as the provider to different language group improves the range of learning globally in spite of the negative influence of the machine translation. This demonstrates that considering the environment of knowledge transmission and communication depending on the property of the group pattern helps maximize the accuracy of the knowledge transmission by the machine translation when we combine the frameworks of organizational learning on the knowledge receiver side. We were also able to develop a transmitting method that is effective for use with machine translation to share very complex or technical knowledge connected mutually. Various challenges remain for our future work. For example, in this study, as the setting of the experiments, the knowledge providers received knowledge about sake production for the first time. Hence, it is necessary to compare with cases where the providers have prior knowledge about some kind of theme. In addition, because we experimented in an environment using Japanese and Chinese only, and translation accuracy is different for every combination of languages, it is necessary to verify whether we get the same knowledge about technical knowledge transmission if we use different languages. We also need to verify the effect of our method with other machine translation services.
This work was supported by a Grant-in-Aid for Scientific Research (S) (24220002, 2012-2016) from the Japan Society for the Promotion of Science (JSPS).

\section{REFERENCES}

[1] Hustad, Eli: Knowledge networking in global organizations: the transfer of knowledge, Proceedings of the 2004 SIGMIS conference on computer personnel research: careers, culture, and ethics in a networked environment, ACM, (2004).

[2] NPO Pangaea: YMC Viet, http://www.pangaean.org/project/ymcprj/?page_id $=37$ (Reference Date: 2015-03-10).

[3] Language Grid Association: Language Grid - Portal Site, http://langrid.org/jp/ (Reference Date: 2015-03-10).

[4] Kita, K., Takasaki, T., Lin, D., Nakajima, Y. and Ishida, T.: Case Study on Analyzing Multi-Language Knowledge Communication, 2012 International Conference on Culture and Computing (Culture and Computing 2012), (2012).

[5] Otani, M., Kita, K., Lin, D., and Ishida, T.: Analysis of Multi-language Knowledge Communication Service in Intercultural Agricultural Support, The 2nd International Conference on Serviceology (ICServ2014), (2014).

[6] Gao, G., et al.: Same translation but different experience: the effects of highlighting on machine-translated conversations, Proceedings of the SIGCHI Conference on Human Factors in Computing Systems, ACM, (2013).

[7] $\mathrm{Xu}, \mathrm{B}$., et al.: Improving machine translation by showing two outputs, Proceedings of the SIGCHI Conference on Human Factors in Computing Systems, ACM, (2014).

[8] Yamashita, N. and Ishida, T.: Effects of machine translation on collaborative work, Proceedings of the 2006 20th anniversary conference on Computer supported cooperative work, ACM, (2006).

[9] Yamashita, N., Inaba, R., Kuzuoka, H., and Ishida, T.: Difficulties in Establishing Common Ground in Multiparty Groups using Machine Translation, Proceedings of ACM Conference on Human Factors in Computing Systems (CHI'09), pp. 679-688, 2009.

[10] Szulanski, G.: The Process of Knowledge Transfer: A Diachronic Analysis of Stickiness, Organizational Behavior and Human Decision Processes, Vol. 82, No. 1, pp. 9-27 (2000).

[11] Multi-lingual Studio: http://langrid.org/developer/en/index.html (Reference Date: 2015-03-10).

[12] Tsunoda, K. and Hishiyama, R.: Design of Multilingual Participatory Gaming Simulations with a Communication Support Agent, SIGDOC '10 Proceedings of the 28th ACM International Conference on Design of Communication, pp. 17-25 (2010).

[13] japan-guide.com: http://www.japan-guide.com/e/e2061.html (Reference Date: 2016-10-26).

\section{ACKNOWLEDGMENTS}

